Review

\title{
Molecular Mechanism of Pancreatic Stellate Cells Activation in Chronic Pancreatitis and Pancreatic Cancer
}

\author{
Guihua Jin, Weilong Hong, Yangyang Guo, Yongheng Bai ${ }^{\bowtie}$, Bicheng Chen ${ }^{\bowtie}$ \\ Key Laboratory of Diagnosis and Treatment of Severe Hepato-Pancreatic Diseases of Zhejiang Province, The First Affiliated Hospital of Wenzhou Medical \\ University, Wenzhou 325000, China \\ $\square$ Corresponding authors: Bicheng Chen, Ph.D., Phone: +86-577-55579309; Fax: +86-577-55578999-660061; E-mail: bisonch@163.com. Yongheng Bai, MD, \\ Phone: +86-577-55579309; Fax: +86-577-55578999-660061; E-mail: wzbyh@wmu.edu.cn. \\ (c) The author(s). This is an open access article distributed under the terms of the Creative Commons Attribution License (https://creativecommons.org/licenses/by/4.0/). \\ See http://ivyspring.com/terms for full terms and conditions.
}

Received: 2019.07.22; Accepted: 2019.12.08; Published: 2020.01.14

\begin{abstract}
Activated pancreatic stellate cells (PSCs) are the main effector cells in the process of fibrosis, a major pathological feature in pancreatic diseases that including chronic pancreatitis and pancreatic cancer. During tumorigenesis, quiescent PSCs change into an active myofibroblast-like phenotype which could create a favorable tumor microenvironment and facilitate cancer progression by increasing proliferation, invasiveness and inducing treatment resistance of pancreatic cancer cells. Many cellular signals are revealed contributing to the activation of PSCs, such as transforming growth factor- $\beta$, platelet derived growth factor, mitogen-activated protein kinase (MAPK), Smads, nuclear factor-KB (NF-KB) pathways and so on. Therefore, investigating the role of these factors and signaling pathways in PSCs activation will promote the development of PSCs-specific therapeutic strategies that may provide novel options for pancreatic cancer therapy. In this review, we systematically summarize the current knowledge about PSCs activation-associated stimulating factors and signaling pathways and hope to provide new strategies for the treatment of pancreatic diseases.
\end{abstract}

Key words: pancreatic stellate cells, fibrosis, signaling pathway, pancreatic cancer, chronic pancreatitis

\section{Background}

Pancreatic cancer, one of the most malignant cancers in the world, affects over 411,600 people annually, and the 5-year survival rate is still below $5 \%$ [1-3]. For the vital roles microenvironment played in cancer progression, more and more attention has been paid to it and histological studies showed that stroma cells, especially PSCs, predominated in pancreatic cancer microenvironment.

Pancreatic stellate cells (PSCs) are resident cells of the pancreas and have become a research hotspot in chronic pancreatitis and pancreatic cancer-related fibrosis [4-8]. Normally, PSCs are quiescent and regulate extracellular matrix (ECM) production. However, during tumorigenesis, stroma cells and pancreatic cancer cells will secret a variety of stimulating factors (e.g. transforming growth factor- $\beta$, TGF- $\beta$ ) to activate PSCs [9]. Then, active PSCs can create a suitable microenvironment and facilitate cancer progression by altering four processes in pancreatic cancer models: (I) excessive fibrosis, (II) promoting tumor metastasis, (III) inducting resistance of chemotherapy and radiotherapy and (IV) immune modulation. There have been plenty of evidences that confirmed the importance of PSCs in pancreatic cancer development. Vonlaufen, Hwang, and Gao et al. demonstrated that the cell supernatant of activated PSCs induced cancer cells proliferation and migration mediated by PDGF and SDF-1/CXCR $[4,8,10]$. It also found that PSCs significantly promoted the growth and metastasis of cancer cells by co-culturing PSCs 
with pancreatic cancer cells [11, 12]. Apte et al. discovered that PSCs can induce tumor-promoting paracrine effects [13]. And Liu et al. found activated PSCs decreased the apoptosis of pancreatic cancer cells induced by gemcitabine [14]. So, it is crucial to find out the active partners and how they work. Therefore, the purpose of this review is to summarize the knowledge about the molecular basis involved in the activation of PSCs in chronic pancreatitis and pancreatic cancer.

\section{Stimulators and PSCs activation}

In recent years, increasing evidence shows that many extracellular signals exert a significant effect on fibrosis development during chronic pancreatitis and pancreatic cancer. These stimulating factors are able to work in the activation of PSCs and may be divided into five groups: (I) cytokines/transcription factors, (II) non-coding RNAs, (III) oxidative stress related factors, (IV) hyperglycemia and (V) ion channels and calcium signaling.

\section{Cytokines/Transcription factors}

\section{TGF- $\beta$}

TGF- $\beta$ is one of the most potent regulatory cytokines of the fibrotic response. It has been observed that increased expression of TGF- $\beta$ in the injured acinar cells which were adjacent to areas of fibrosis [15]. TGF- $\beta 1$ could activate MAPKs signal pathway and induce an enhanced mRNA expression level of JNK1 and ERK1, which then leading PSCs to differentiate into myofibroblasts that could secret a variety of ECM, such as type I collagen and fibronectin [16-18]. Further studies have demonstrated that PSCs synthesize TGF- $\beta 1$ itself, which suggesting the possible existence of autocrine loops that may contribute to the continuous activation of PSCs after an initial exogenous signal [19]. Vogelmann et al. found that on the 14th day after birth of TGF- $\beta 1$ overexpressing transgenic mice that have the morphological features of chronic pancreatitis, the fibrous tissue was mainly composed of type I and III collagens [16]. And on 70th day, the elevated deposition of laminin amounted to the over-synthesis of ECM. PSCs were the principal cellular source of type I collagen in pancreatic fibrosis in both humans and in an experimental animal model. Taking advantage of trans retinoic acid, that could weaken the biological activity of TGF- $\beta$, hampered the active myofibroblast PSCs phenotype, which is strongly associated with tumor growth and metastasis $[20,21]$. So, this indicating that TGF- $\beta 1$ was possibly responsible for pancreatic fibrosis through the activation of PSCs.

In addition, activin $A$, a member of the TGF- $\beta$ superfamily, was detected to work with TGF- $\beta 1$ and increased each other's secretion and mRNA expression in PSCs [22-24]. And taking advantage of endogenous binding protein for them could reverse PSCs activation (e.g. follistatin) [25]. However, it still needs fuither study to find out the details and tell the differences between TGF- $\beta 1$ and activin A in PSCs activation.

\section{Connective tissue growth factor (CTGF)}

CTGF is the member of the CNN family proteins. Studies have shown that CTGF, similar to TGF- $\beta$, is an autocrine regulator of PSCs [26, 27]. It has been known that CTGF was produced at the injury site by acinar cells or fibroblastic cells, and these fibroblastic cells, produced the highest level of CTGF, were likely include a population of activated PSCs [28, 29]. Besides,

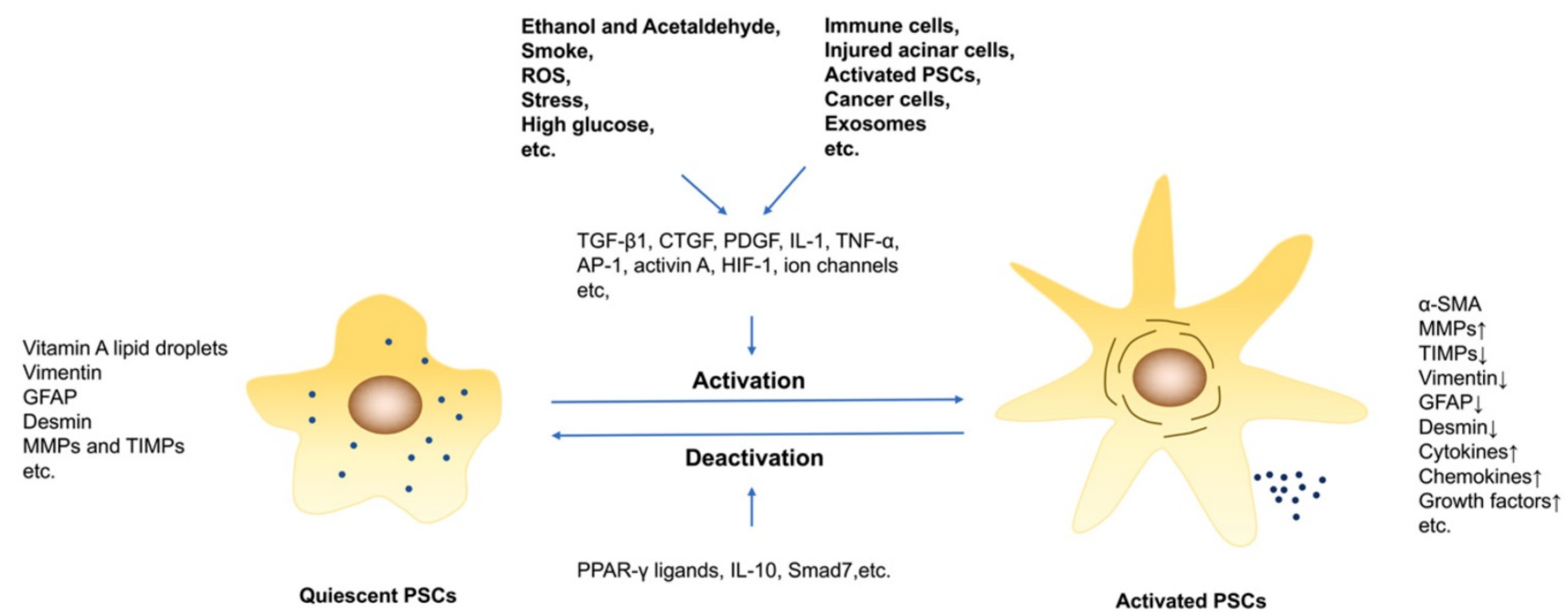

Figure 1. The activation and deactivation of PSCs. PSCs are activated by profibrogenic mediators, such as ethanol, high glucose and cytokines. And persisting of PSCs activation under pathological conditions results in pancreatic fibrosis. 
it can also affect PSCs activation by TGF- $\beta[30,31]$. Abreu et al. found that the presence of CTGF would increase the cross-linking between TGF- $\beta 1$ and all of its receptor binding proteins [31, 32]. Neutralizing antibody of CTGF inhibited the fibrotic effects of TGF- $\beta 1$, suggesting that CTGF and TGF- $\beta 1$ may have a synergistic effect. Moreover, TGF- $\beta 1$ could also activate the CTGF promoter in a short term [30]. And down-regulation of CTGF/CCN2 expression by small interfering RNA caused a reduction of PSC proliferation [27].

\section{Interleukin-10 (IL-10)}

IL-10, another important autocrine regulator of PSCs, is a potent anti-inflammatory and anti-fibrotic cytokine produced by Th2 cells [33]. Endogenous IL-10 might directly limit the atrophy and fibrosis of pancreatic gland by downregulating procollagen I and enhancing collagenase gene expression[34-37]. Meanwhile, it cuts down the release and expression of TGF- $\beta$ in the pancreatic acinar and stromal cells [38-40]. Demols et al. revealed that IL-10 deficient chronic pancreatitis mice had severer damage and fibrosis of pancreatic tissue, and the level of plasma TGF- $\beta 1$ and the number of activated PSCs were all significantly raised as well [38]. So, IL-10 is probably an effective target to inhibit the pancreatic fibrosis.

\section{Platelet derived growth factor (PDGF)}

PDGF is mainly synthesized by inflammatory cells and is a crucial stimulator in activating PSCs and forming of ECM [41, 42]. PDGF family consists of four different polypeptide chains encoded by four different genes: four homodimers of $\mathrm{A}, \mathrm{B}, \mathrm{C}$ or $\mathrm{D}$ subunits and one heterodimer $\mathrm{AB}$. And they act via two receptor tyrosine kinases, PDGF receptors (PDGFR) $\alpha$ and $\beta$ [43]. It has been shown that the expression of PDGFR- $\beta$ in PSCs correlates with the prognosis of patients with pancreatic cancer [44]. However, detailed molecular mechanisms remain unclear. In vitro, activated PSCs express PDGFR-a and PDGFR- $\beta$ [15, 45, 46]. PDGF-BB induces the phosphorylation of PDGFR- $\beta$, and subsequently activates phosphatidylinositol 3 kinase (PI3K) and extracellular regulated protein kinase (ERK) pathways [46]. ERK pathway regulates the proliferation and migration of PSCs, and blocking the ERK pathway could completely suppress the proliferation and almost $50 \%$ cell migration of PSCs $[46,47]$. However, inhibition of PI3K pathway did not affect PDGF-BB induced proliferation [46]. Thus, PDGF is the most potent mitogen for PSCs proliferation, and stimulates the synthesis of collagen and fibronectin as well $[46,48]$.

\section{Hypoxia inducible factor-1 $\alpha$ (HIF-1)}

Hypoxia contributes to the development of pancreatic diseases. Recent studies have shown that a hypoxic environment exists not only in cancer cells, but also in surrounding PSCs [49]. The response of the PSCs to hypoxia is achieved by HIF-1 which is a heterodimeric protein containing both $\alpha$ and $\beta$ subunits. HIF-1 $\beta$ expresses in normoxia, while HIF-1 $\alpha$ only accumulates in the state of hypoxia. Subsequently, HIF-1a translocates to the nucleus and participates in the transcription of vascular endothelial growth factor and other pro-fibrotic genes in PSCs [50]. Activated HIF-1a could also mediate the upregulation hepatoma-derived growth factor gene which finally contributes to the antiapoptosis of PSCs and consequently leads to the synthesis and deposition of ECM proteins [51].

\section{Non-coding RNAs}

Recently, numerous families of non-coding RNAs, especially microRNAs (miRNAs), have attracted the attention of researchers for their dramatically altered expression profiles during the PSCs activation [52].

Some miRNAs expressions are beneficial to PSCs activation. Masamune et al. found that pancreatic cancer cell-derived exosomes could increase the activity of PSCs and also induce their fibrosis-related gene expression by miR-1246 and miR-1290 [53]. Connective tissue growth factor (CCN2) and miR-21 are components of PSCs-derived exosomes which are significantly up-regulated in activated PSCs. The expression level of CCN2 drives miR-21 induction which acts via positive feedback loop to potentiate CCN2 production, and finally amplifying collagen production in the cells. It's revealed that exosomes, containing miR-21 and CCN2 transcripts, enabled their uptake by other PSCs and influenced the phenotypes of PSCs $[54,55]$. And the transfection of active anti-miRNA-199a oligonucleotide into human PSCs could lead to the inhibition of PSCs activation and differentiation into cancer-associated fibroblasts $[56,57]$.

However, some miRNAs have the opposite effect. Asama et al. found that the miRNA let-7d-5p inhibited the activation of human PSCs by targeting thrombospondin 1 and downstream TGF- $\beta$ pathway $[58,59]$. Wang et al. reported that the inhibition of syntaxin-12 lncRNA, which making miR-148a upregulated and Smad5 decreased, ultimately resulting in the suppression of PSC activation [60]. Liu et al. had a similar discovery that lncRNA myocardial infarction-associated transcript contributed to PSCs activation through suppressing miR-216a-3pmediated COX-2, which finally leading to pancreatic 
fibrosis [61]. Same studies also uncover the inhibitory effect of miR-200a in PSCs activation [62].

Since more and more studies have found the roles of miRNAs in PSC activation, further studies are needed to investigate where are the exact origins of these miRNAs, PSCs or cancer cells, and how they really work.

\section{Oxidative stress related factors}

According to experimental chronic pancreatitis and clinical observations, oxidative stress exerts an enormous function on PSCs activation and pancreatic fibrosis. Exogenous $\mathrm{H}_{2} \mathrm{O}_{2}$, a traditional cellular reactive oxygen species (ROS) inducer, promoted PSCs a-smooth muscle actin (a-SMA) production and migration [55]. Zeki et al. revealed that the level of oxygen free radicals elevated with the change of pancreatic fibrosis in $\mathrm{wBN} / \mathrm{Kob}$ rats and reduced the activity of SOD [63]. Applying DA-9601, an anti-oxidant chemical substance, the inflammation and myeloperoxidase activity of chronic pancreatitis mice were both decreased, and the expression of a-SMA and type I collagen in isolated PSCs also reduced [64]. In recent years, coenzyme Q10, a powerful antioxidant, was also found could ameliorate pancreatic fibrosis via reducing intracellular levels of ROS in PSCs $[65,66]$.

Ethanol and smoking are now recognized as important risk factors for chronic pancreatitis. It's largely because both pancreatic acinar cells and PSCs metabolize ethanol to generate oxidative stress that promote PSCs activation and lipid peroxidation [67, 68]. Meanwhile, ethanol and its metabolites also upregulated the activity of MAPK pathway and the expression of a-SMA in PSCs [69]. SB203580, which was used to block p38 kinase, inhibited the spontaneous activation of PSCs, suggesting that it was p38 MAPK pathway which took effects on PSCs activation. As for smoke, previously studies reported that nicotine and nicotine-derived nitrosamine ketone and cigarette smoke extracts induced nAChR (isoforms $\alpha 3, \alpha 7, \beta, \varepsilon$ ) expression in the cells [70], and increased production of ROS in PSCs [71]. Aryl hydrocarbon receptor ligands in cigarette smoke could upregulate IL-22 in PSCs which induced the expression of the extracellular matrix genes fibronectin 1 and collagen type I a1 chain [72]. However, the mechanisms mediating the effects of smoking on PSC activation are still largely unknown.

Ductal hypertension has been believed to be a major contributor of biliary pancreatitis. Asaumi et al. found that pressure could induce PSCs activation and increase ROS level in activated PSCs [73]. And Watanabe et al. found that enhanced pressure mainly induced the 5-bromodeoxyuridine incorporation and
a-SMA expression [74]. In addition, intracellular pressure rapidly elevated the phosphorylation of ERK and p38 MAPK and promoted the secretion of TGF- $\beta 1$ and collagens. The antagonists of mitogen-activated extracellular signal-regulated kinase (MEK) and p38 MAPK inhibited stress-induced a-SMA expression and cell proliferation. Thus, increasing pressure of pancreatic tissue may accelerate the progress of fibrosis in chronic pancreatitis by activating PSCs.

Therefore, the above studies suggest that oxidative stress related factors play a role in the occurrence of pancreatic injury and fibrosis, to some extent, by activating PSCs.

\section{Hyperglycemia}

Observations from previous studies have showed that high glucose resulted in more a-SMA and ECM proteins expression [75]. Subsequently, researchers indicated that high glucose may activate PSCs through p38 MAPK pathway and finally resulted in increased ECM production [76, 77]. And chronic hyperglycemia could not only activate PSCs, but also promote the interaction of PSCs and pancreatic cancer cells [78]. Increasing attentions still need to be directed towards the role of hyperglycemia in PSCs activation.

\section{Ion channels and calcium signaling}

Besides, growing evidence has revealed the crucial role of calcium signaling and ion channels played in PSCs stimulated by the above factors [79-86]. Schwab et al. found that several members of the transient receptor potential (TRP) family contributed to PSCs activation. In pressure-induced PSCs activation, transient receptor potential canonical 1 (TRPC1)-mediated calcium influx was increased [81]. However, knockout of TRPC1 led not only to attenuated phenotype and cytokine production, but also a reduced $\mathrm{Ca}^{2+}$ influx in PSCs. As for TRPC3, PDGF could stimulate migration of PSCs in a $\mathrm{K}_{\mathrm{Ca}} 3.1$ channel dependent manner, and knockdown of TRPC3 channels largely abolished this impact on PSC migration for their provision with $\mathrm{Ca}^{2+}$ required for channel activation [80]. Similar as the function of TRPC1 channels, hypoxia could also induce PSCs activation in a TRPC6-dependent manner [79]. In addition, Yule and Petersen et al. proposed a novel idea of PSCs activation. They found PSCs in their normal microenvironment are far from quiescent, they can generate substantial cytosolic $\mathrm{Ca}^{2+}$ signals in response to the stimulation of the blood pressure-lowering nona-peptide bradykinin and some other substances $[83,84]$. However, more efforts still need to be taken to work out the actual state of PSCs activation. 


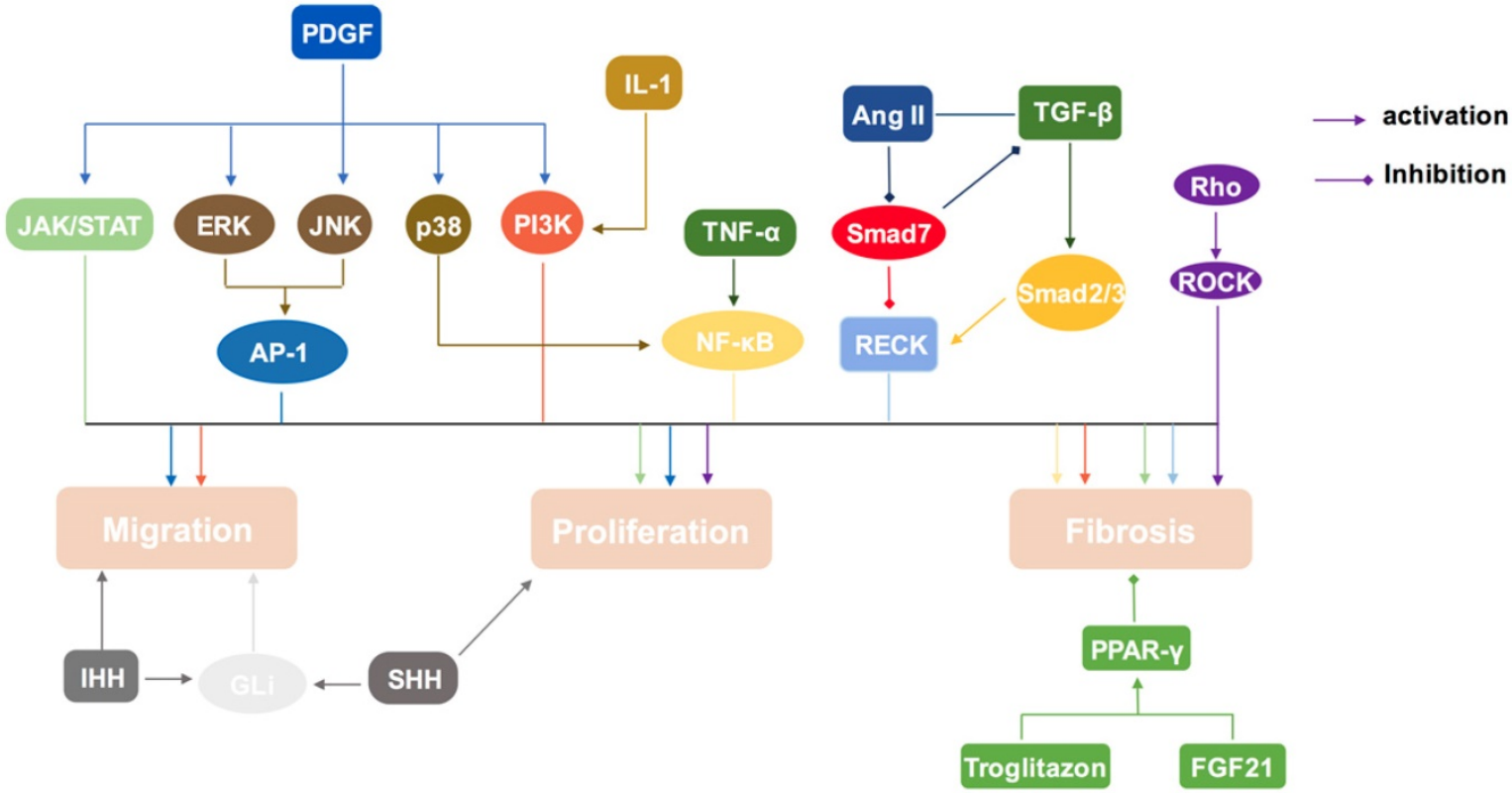

Figure 2. Signal transduction pathways in PSCs activation. PSCs can be activated by MAPK, Rho/ROCK, NF-KB, PI3K/AKT, JAK/STAT, and sonic hedgehog-Glil pathway. Smads pathway play a dual role in this process. And PPAR-y pathway will inhibit the activation of PSCs.

\section{Signaling pathways and PSCs activation}

Accumulating studies are aiming at seeking methods to inhibit or reverse the activation of PSCs, which finally amounts to preventing or delaying the fibrosis process in pancreatic diseases. PSCs activation involves in several important signal transduction pathways (Table 1, Figure 2). Thus, deeply exploring the role of these pathways is of great significance in the treatment of chronic pancreatitis and pancreatic cancer.

Table 1. The signal transduction pathways in PSCs

\begin{tabular}{lll}
\hline Pathway & Function & Reference \\
\hline MAPK(ERK) & Migration, Proliferation & {$[90,94-96]$} \\
MAPK(JNK) & Migration, Proliferation, Cytokine production & {$[17,46,97,99,100]$} \\
MAPK(p38) & Fibrosis, a-SMA expression & {$[69,102,103]$} \\
Rho/ROCK & Fibrosis, Proliferation, Chemotaxis & {$[73,104,105]$} \\
NF-KB & Fibrosis & {$[106,108-110]$} \\
PPAR-y & Anti-fibrosis, Maintain the quiescence & {$[111-118]$} \\
PI3K/Akt & Migration, Fibrosis & {$[103,119-123]$} \\
JAK/STAT & Proliferation, Fibrosis & {$[48,131-133]$} \\
Smads & Dual role of fibrosis & {$[96,137-141]$} \\
Hedgehog & Migration, Proliferation & {$[142-146]$} \\
\hline
\end{tabular}

\section{MAPKs}

Previous research reported that MAPK signaling pathway was involved in the early phase of acute pancreatitis [87]. In respond to extracellular stimuli, MAPKs take effects on many cellular events, such as proliferation, apoptosis and survival, and can upregulate the expression of inflammatory cytokines in the pancreas $[88,89]$. The central members of the MAPKs (ERK, JNK, and p38 MAPK) could transduce signals that are generated by cytokines, growth factors, and intracellular stress. ERK, JNK, and p38 MAPK have been reported increased in mice chronic pancreatitis model, and PSCs were the source of producing MAPKs [17].

Cascade performance in ERK signaling pathway is starting from stimulating receptor tyrosine kinases (RTKs), and then activating of Raf and RasGTP enzyme. ERK, which is activated by Raf, translocates to the nucleus to regulate transcription factors, such as activator protein-1 (AP-1) [90]. AP-1 is a transcription factor which can be phosphorylated by the mitogen-activated protein kinase (MAPK) family members [91, 92]. Owing to MAPK pathway is involved in the PSCs activation, it suggests that AP-1 may also refer to activate PSCs $[46,93]$. Schwer et al. reported that curcumin induced the expression of oxygenase-1 (HO-1) gene, thereby suppressing the activation of ERK $1 / 2$ and subsequently inhibiting the proliferation of PSCs [94]. Adding ERK inhibitors to PSCs, the expressions of CX3CR1 and SMA in PSCs decrease dramatically, suggesting that ERK 1/2 may participate in the process of fibrosis by regulating chronic pancreatitis-related cytokines [95]. Above all, studies have shown that ERK pathway acts on the migration, activation and matrix synthesis of PSCs [96].

C-Jun amino terminal kinase (JNK) is phosphorylated by MAP3Ks (such as ASK1, MEKK1, MLK3) and MAP2Ks (such as MKK4, MKK7) after activated by cytokines, pressure and other factors [97]. Phosphorylated JNK binds to activating transcription factor 2 (ATF2) through the amino terminal domain of c-Jun to form a dimer that enhances the 
transcriptional activity of AP-1. Fitzner et al. found that the presence of JunD in AP-1 complexes was typical for activated PSCs, while the portion of JunB-containing AP-1 complexes decreased during the process of activating PSCs, along with the overall decrease of AP-1 DNA binding activity as well [98]. And in freshly isolated PSCs, the JNK inhibitor curbs IL-1 $\beta$-induced activities of JNK and AP-1, as well as the PDGF-mediated activation of PSCs [99]. Studies of knockout mice have shown that MAPK phosphatase (MKP) plays a negative regulatory role in JNK pathway, and the use of reactive oxygen species (ROS) to inhibit MKP activity can prolong the activation of JNK [100]. Moreover, JNK and ERK were believed respond directly to TGF- $\beta 1$ and PDGF, which are considered as the most important factors of PSCs proliferation and ECM deposition $[17,46]$.

p38, a kind of stress-activated protease (SAPK), is activated by a variety of proinflammatory-related factors, and takes an effect on apoptosis, transcriptional regulation, cytokine production and cytoskeleton recognition [101]. Freshly isolated mouse PSCs were treated with SB203580, a specific inhibitor of p38 MAPK, and the levels of a-SMA and type I collagen in PSCs were significantly reduced [102]. Seven days Later, the activation of PSCs was not observed yet, indicating that activated p38 MAPK may participate in PSCs activation. Apte et al. reported that antagonizing p38 MAPK other than ERK or JNK pathways, inhibited PSCs activation and a-SMA expression, suggesting that p38 probably plays a major role in acetaldehyde-mediated PSCs activation [103]. Although ethanol and acetaldehyde-induced PSCs activation could upregulate the ERK $1 / 2$ and p38 expression, only the inhibition of the p38 MAPK pathway decreased a-SMA expression and the activation of PSCs [69, 103].

Nevertheless, the specific mechanisms need further exploration.

\section{Ras homolog gene family/rho-associated protein kinase (Rho/ROCK)}

Studies have shown that small GTP-binding protein Rho and its downstream effector ROCK act on actin cytoskeleton, stress fibers and cell morphology [104]. It is reported that the expression of stress fibers on the surface of activated PSCs increases before the whole cells are filled with stress fibers. Y-27632 and HA-1077, specific inhibitors for ROCK, prevent spontaneous activation of PSCs [73, 105]. The stress fibers decompose gradually after Y-27632 acting on activated PSCs, indicating that PSCs activation is related to Rho/ROCK pathway. Additionally, Y-27632 reduces the expression of a-SMA, one of the markers of PSCs activation, hinders the proliferation and chemotaxis of PSCs mediated by PDGF, and prevents the production of collagens. Thus, it is implicating that Rho/ROCK pathway not only induces PSCs active, but also promotes its proliferation and chemotaxis.

\section{NF-KB}

The pleiotropic transcription factor NF- $\mathrm{KB}$ is composed of homologous or heterodimer of the Rel protein family members (p65, p50, p52, c-Rel, and RelB). In mammalian cells, the synthesis of classic NF-kB complex, constituted by p65/p50 heterodimer, could be triggered by cytokines, mitogen, ultraviolet and other stimulating factors, such as tumor necrosis factor- $\alpha$ (TNF- $\alpha$ ) and IL-1 [106]. TNF- $\alpha$ and IL-1 induce activated PSCs to express IL-6, IL- 8 and monocyte chemoattractant protein-1 (MCP-1) through the AP-1, which are target genes of NF- $\mathrm{KB}$, showing that NF-KB activation may promote pancreatic fibrosis through PSCs [93, 107, 108]. Recent studies have shown that Bay11-7082, the specific blocker of NF-kB, hamper NF-kB pathway by clearing up MCP-1, IL-8 or nitric oxide synthase (NOS) that are induced by Toll-like receptor (TLR) and galactin-1, demonstrating that TLR and galactin-1 may promote PSCs activation and fibrosis through NF-KB pathway [109]. Further study found that pancreatic ductal adenocarcinoma (PDAC)-derived galactin-3 activated PSCs and promoted PSCs secretion of proinflammatory factors (IL8, CCL2, and CXCL1) through ITGB1/ILK/NF-kB signaling cascade [110].

\section{Peroxisome proliferator activated receptor- $Y$ (PPAR-Y)}

PPAR-y, a nuclear hormone receptor, is involved in adipocyte differentiation, proliferation, immune response, and insulin secretion in adipose tissue and immune system [111]. The researchers reveal that the expression of PPAR- $\gamma$ is negatively correlated with PSCs proliferation, and the ligand of PPAR- $\gamma$, Troglitazone, can reduce a-SMA expression and PSCs proliferation by PPAR- $\gamma$ signaling [112], making the activated PSCs transform to the stationary state [113]. Consequently, it alleviates the process of pancreatic inflammation and fibrosis, and finally meliorated the development of chronic pancreatitis in animal models [114-117]. Johnson et al. reported that fibroblast growth factor 21 (FGF21) is an important factor involved in lipid metabolism that regulates the activity of PSCs through PPAR-ץ pathway [118].

\section{PI3K-Serine/threonine kinase (AKT)}

The PI3K family is a class of kinases that specifically catalyses the phosphorylation of 
PI3-hydroxyl groups to produce inositol ester material that acts as a second messenger. PI3K attracts Akt (called protein kinase B) into the cell membrane during phosphorylation [119]. PI3K/Akt pathway exerts an effect on cell proliferation, anti-apoptotic, migration, transmembrane translocation and cell carcinogenesis [120]. It's known that IL-1 $\beta$, TNF- $\alpha$ and IFN- $\gamma$ regulate the activity of PSCs to express IL-32a that triggers fibrosis, and the inhibitor of PI3K downregulates IL-32 $\alpha$ expression in response to the stimuli [121]. Nishida et al. reported that PDGF regulated the migration of PSCs by activating the PI3K/Akt pathway [121, 122]. What's more, this pathway had a cross effect with the MAPK pathway in aldehydes-induced PSCs activation [103]. Blockade of the PI3K/Akt pathway with carbon monoxide releasing molecule-2 (CORM-2) led to down-regulation of cyclin D1 or E and arrestment in $\mathrm{G}_{0} / \mathrm{G}_{1}$, and finally inhibited the activation of PSCs $[123,124]$. However, recently, Cui et al have found that activating the $\mathrm{PI} 3 \mathrm{~K} / \mathrm{Akt} / \mathrm{mTOR}$ pathway could inhibit autophagy and further suppress PSCs activation [125-127]. They also suggested that TGF- $\beta 1$ might be regulated by PI3K/Akt pathway, but the significance of this crosstalk still required further study [128-130].

\section{Janus-activated kinase (JAK)/signal transducer and activator of transcription (STAT)}

JAK is a group of receptor-deficient tyrosine kinases activated by phosphorylating transcription factor STAT [131]. The STAT proteins are present in the cytoplasm as precursor proteins, and the tyrosine residue is phosphorylated and translocated to the nucleus to bind to the specific DNA. It's known that PDGF promotes the proliferation of PSCs through the JAK/STAT pathway [48]. PDGF-mediated activation of STAT1 and STAT3 was blocked by the inhibitors of Src and JAK2, resulting in the reduction of fibrosis [132]. Therefore, it's speculated that the activation of the Src-dependent JAK/STAT pathway is involved in PSCs activation and PDGF-mediated fibrosis. In pancreatic acinar cells, bombesin activates the JAK/STAT pathway via nitrogen oxides (NOX). In PSCs, ROS may also contribute to the activation of NF-kB and JAK/STAT pathways in the development of acute pancreatitis [133].

\section{Smads}

The Smads family, a group of small molecules that regulate intracellular signals, has been found to have at least nine members that divided into three groups, including pathway restriction proteins [134], co-mediated type proteins [135], and inhibitory proteins [136]. It's reported that Smads are functionally dynamic in PSCs [137]. Firstly, TGF- $\beta$ promotes Smad2, 3 and 4 to form a polymer and subsequently enters the nucleus to regulate the transcription of the target gene. TGF- $\beta$ promotes the fibrosis of pancreas through Smad2 or Smad3 pathway, however, inhibits the expression of Smad7 [96]. Moreover, angiotensin II inhibits the expression of Smad7 mRNA through the PKC pathway, and promotes the TGF- $\beta$-mediated proliferation of PSCs [138]. Smad4, a key downstream protein for TGF- $\beta /$ Smad pathway, regulates plasminogen activator inhibitor 1 (PAI-1) and participates in the production of ECM. Smad3/4 binds to two adjacent Smad-binding sites in TGF- $\beta$ reaction region and initiates the transcription of PAI-1 to increase the precipitation of ECM afterward. The interaction of Smad7 with TGF- $\beta$ receptor (T $\beta$ R) blocks TGF- $\beta$ signal translocation to the nucleus and the phosphorylation of Smad2/3, thereby preventing PSCs activation. After the treatment of TGF- $\beta$, decreased Smad7 and raised Smad3 expression, and gradually activated PSCs are all in a concentration-dependent manner. Smad7 also hampers the overexpression of tissue inhibitor of metalloproteinases (TIMPs) that mediated by TGF- $\beta$, reducing the formation of collagen fibers and deposition of ECM [138].

The reversion-inducing-cysteine-rich protein with kazal motifs (RECK), a kind of PSC membrane anchor proteins, regulates the activity of cell surface matrix metalloproteinases (MMPs). Pancreatic acute phase protein and chronic time-dependent protein can downregulate RECK protein expression, thereby affecting the activity of MMPs and the metabolism of ECM [139]. The expression of RECK is regulated by Smads system, and Smad7 overexpression or decreased Smad3 expression may result in reduced RECK [140]. Bone morphogenetic protein 2 (BMP2), a member of the TGF- $\beta$ family, is able to bind the receptor to phosphorylate Smad1/5/8. Gao et al. reported that the level of BMP was high in pancreatic tissue induced by bombesin, and the deletion of BMP2 increased fibrosis in chronic pancreatitis rats [141]. Consequently, it is expected that the anti-fibrosis effect of BMPR2-Smad1/5/8 signaling pathway works through inhibiting TGF- $\beta / \operatorname{Smad} 2$ and p38 pathway in pancreas.

\section{Hedgehog}

Sonic hedgehog (Shh) and indian hedgehog (Ihh) are the major members of the Hedgehog family. Shinozaki et al. found that activated PSCs expressed patched-1 (Ptch1) and smoothened (Smo) which were both important components of the Hedgehog receptor system [142]. Ihh enhances the migration of PSCs in 
terms of chemotaxis and chemical activation, and increases the expression of MMP1 which degrades the basement membrane to promote cell movement. TIMP2 can attenuate the migration of PSCs caused by Ihh stimulation. Most of the hedgehog intercellular signal transductions are regulated by the transcription factor Gli1. And Ihh induces the accumulation of Gli1 in the nucleus of PSCs, suggesting that Ihh may activate Gli1-dependent signaling pathways. Shh which produced by pancreatic cancer cells is able to activate quiescent PSCs, induce them to express Gli1 and further promote cell migration [143-145]. Accordingly, hedgehog signaling is an indispensable pathway in the activation of PSCs and the production of ECM during fibrosis in chronic pancreatitis and pancreatic cancer [146].

\section{Conclusion}

In recent years, increasing attention has been directed to the role of activated PSCs in pancreatic diseases, especially chronic pancreatitis and pancreatic cancer. Quiescent PSCs are involved in maintenance of pancreatic tissue architecture and maintain ECM turnover [147]. However, activated PSCs exhibit deranged ECM turnover and contribute to inflammatory microenvironment. Although a few prominent publications described that the presence of stroma rich in activated PSCs greatly restrained tumor progression [148, 149], it is still an exciting challenge to understand the detailed mechanisms that govern the process of PSCs phenotype transition in the distinct phases of pancreatic inflammation and tumorigenesis. As described above, we have some knowledge about PSCs activation. Nevertheless, still much has to be learned. Making the complex networks in PSCs activation clear will help us to explore deeply about the molecular mechanism of pancreatic fibrosis and probably help to aid the development of novel therapeutic strategies against pancreatic cancer.

\section{Abbreviations}

AP-1: activator protein-1; Ang II: Angiotensin II; a-SMA: a-smooth muscle actin; CTGF: connective tissue growth factor; ECM: extracellular matrix; ERK: extracellular regulated protein kinase; FGF21: fibroblast growth factor 21; GFAP: glial fibrillary acidic protein; HIF-1: hypoxia-inducible factor; IHH: indian hedgehog; IL: interleukin; JNK: c-Jun N-terminal kinase; JAK/STAT: janus-activated kinase/signal transducer and activator of transcription; MAPK: mitogen-activated protein kinase; NF-kB: nuclear factor-kB; PI3K/Akt: phosphatidylinositol 3 kinase-serine/threonine kinase; PSCs: pancreatic stellate cells; PPAR-y: peroxisome proliferator activated receptor- $\gamma$; MMPs: matrix metalloproteinases; PDGF: platelet derived growth factor; RECK: the reversion-inducingcysteine-rich protein with kazal motifs; Rho/ROCK: ras homologue gene family/rho-associated protein kinase; RTKs: receptor tyrosine kinases; $\mathrm{SHH}$ : sonic hedgehog; TGF- $\beta 1$ : transforming growth factor- $\beta 1$; TIMPs: tissue inhibitor of metalloproteinases; TNF: tumor necrosis factor; TRP: transient receptor potential; TRPC1: transient receptor potential canonical 1.

\section{Acknowledgements}

We are thankful to Dr. Abdullahi Mohamed Said (Wenzhou Medical University, Wenzhou, China) for his linguistic assistance during the preparation of this manuscript.

\section{Author Contributions}

Guihua Jin drafted the work. Weilong Hong, Yangyang Guo and Yongheng Bai substantively revised it. Bicheng Chen designed this work. All authors read and approved the final manuscript.

\section{Competing Interests}

The authors have declared that no competing interest exists.

\section{References}

1. Global, regional, and national life expectancy, all-cause mortality, and cause-specific mortality for 249 causes of death, 1980-2015: a systematic analysis for the Global Burden of Disease Study 2015. Lancet. 2016; 388: 1459-544.

2. McGuire S. World Cancer Report 2014. Geneva, Switzerland: World Health Organization, International Agency for Research on Cancer, WHO Press, 2015. Adv Nutr. 2016; 7: 418-9.

3. Egawa S, Toma H, Ohigashi H, Okusaka T, Nakao A, Hatori T, et al. Japan Pancreatic Cancer Registry; 30th year anniversary: Japan Pancreas Society. Pancreas. 2012; 41: 985-92.

4. Hwang RF, Moore T, Arumugam T, Ramachandran V, Amos KD, Rivera A, et al. Cancer-associated stromal fibroblasts promote pancreatic tumor progression. Cancer Res. 2008; 68: 918-26.

5. Jaster R. Molecular regulation of pancreatic stellate cell function. Mol Cancer. 2004; 3: 26.

6. Pinzani M. Pancreatic stellate cells: new kids become mature. Gut. 2006; 55: $12-4$.

7. Omary MB, Lugea A, Lowe AW, Pandol SJ. The pancreatic stellate cell: a star on the rise in pancreatic diseases. J Clin Invest. 2007; 117: 50-9.

8. Vonlaufen A, Joshi S, Qu C, Phillips PA, Xu Z, Parker NR, et al. Pancreatic stellate cells: partners in crime with pancreatic cancer cells. Cancer Res. 2008; 68: 2085-93

9. Bachem MG, Zhou Z, Zhou S, Siech M. Role of stellate cells in pancreatic fibrogenesis associated with acute and chronic pancreatitis. J Gastroenterol Hepatol. 2006; 21 Suppl 3: S92-6.

10. Gao Z, Wang X, Wu K, Zhao Y, Hu G. Pancreatic stellate cells increase the invasion of human pancreatic cancer cells through the stromal cell-derived factor-1/CXCR4 axis. Pancreatology. 2010; 10: 186-93.

11. Fujita H, Ohuchida K, Mizumoto K, Egami T, Miyoshi K, Moriyama T, et al. Tumor-stromal interactions with direct cell contacts enhance proliferation of human pancreatic carcinoma cells. Cancer Sci. 2009; 100: 2309-17.

12. Marzoq AJ, Mustafa SA, Heidrich L, Hoheisel JD, Alhamdani MSS. Impact of the secretome of activated pancreatic stellate cells on growth and differentiation of pancreatic tumour cells. Sci Rep. 2019; 9: 5303.

13. Apte MV, Wilson JS, Lugea A, Pandol SJ. A starring role for stellate cells in the pancreatic cancer microenvironment. Gastroenterology. 2013; 144: 1210-9.

14. Liu SL, Cao SG, Li Y, Sun B, Chen D, Wang DS, et al. Pancreatic stellate cells facilitate pancreatic cancer cell viability and invasion. Oncol Lett. 2019; 17: 2057-62. 
15. Haber PS, Keogh GW, Apte MV, Moran CS, Stewart NL, Crawford DH, et al. Activation of pancreatic stellate cells in human and experimental pancreatic fibrosis. Am J Pathol. 1999; 155: 1087-95.

16. Vogelmann R, Ruf D, Wagner M, Adler G, Menke A. Effects of fibrogenic mediators on the development of pancreatic fibrosis in a TGF-beta1 transgenic mouse model. Am J Physiol Gastrointest Liver Physiol. 2001; 280: G164-72.

17. Xu XF, Liu F, Xin JQ, Fan JW, Wu N, Zhu LJ, et al. Respective roles of the mitogen-activated protein kinase (MAPK) family members in pancreatic stellate cell activation induced by transforming growth factor-beta1 (TGF-beta1). Biochem Biophys Res Commun. 2018; 501: 365-73.

18. Gao X, Cao Y, Yang W, Duan C, Aronson JF, Rastellini C, et al. BMP2 inhibits TGF-beta-induced pancreatic stellate cell activation and extracellular matrix formation. Am J Physiol Gastrointest Liver Physiol. 2013; 304: G804-13.

19. Shek FW, Benyon RC, Walker FM, McCrudden PR, Pender SL, Williams EJ, et al. Expression of transforming growth factor-beta 1 by pancreatic stellate cells and its implications for matrix secretion and turnover in chronic pancreatitis. Am J Pathol. 2002; 160: 1787-98.

20. Froeling FE, Feig C, Chelala C, Dobson R, Mein CE, Tuveson DA, et al. Retinoic acid-induced pancreatic stellate cell quiescence reduces paracrine Wnt-beta-catenin signaling to slow tumor progression. Gastroenterology. 2011; 141: 1486-97, 97 e1-14.

21. Sarper M, Cortes E, Lieberthal TJ, Del Rio Hernandez A. ATRA modulates mechanical activation of TGF-beta by pancreatic stellate cells. Sci Rep. 2016; 6: 27639.

22. Ohnishi N, Miyata T, Ohnishi H, Yasuda H, Tamada K, Ueda N, et al. Activin $A$ is an autocrine activator of rat pancreatic stellate cells: potential therapeutic role of follistatin for pancreatic fibrosis. Gut. 2003; 52: 1487-93

23. Yasuda H, Inoue K, Shibata H, Takeuchi T, Eto Y, Hasegawa Y, et al. Existence of activin-A in A- and D-cells of rat pancreatic islet. Endocrinology. 1993; 133: 624-30.

24. Bachman KE, Park BH. Duel nature of TGF-beta signaling: tumor suppressor vs. tumor promoter. Curr Opin Oncol. 2005; 17: 49-54.

25. Krizhanovsky V, Yon M, Dickins RA, Hearn S, Simon J, Miething C, et al. Senescence of activated stellate cells limits liver fibrosis. Cell. 2008; 134: 657-67.

26. Apte MV, Haber PS, Applegate TL, Norton ID, McCaughan GW, Korsten MA, et al. Periacinar stellate shaped cells in rat pancreas: identification, isolation, and culture. Gut. 1998; 43: 128-33.

27. Karger A, Fitzner B, Brock P, Sparmann G, Emmrich J, Liebe S, et al. Molecular insights into connective tissue growth factor action in rat pancreatic stellate cells. Cell Signal. 2008; 20: 1865-72.

28. di Mola FF, Friess H, Martignoni ME, Di Sebastiano P, Zimmermann A, Innocenti $\mathrm{P}$, et al. Connective tissue growth factor is a regulator for fibrosis in human chronic pancreatitis. Ann Surg. 1999; 230: 63-71.

29. Charrier AL, Brigstock DR. Connective tissue growth factor production by activated pancreatic stellate cells in mouse alcoholic chronic pancreatitis. Lab Invest. 2010; 90: 1179-88

30. Sun YW, Zhang YP, Qiao MM, Fu H, Yuan YZ. The study of regulation of connective tissue growth factor gene promoter by transforming growth factor beta1 in pancreatic stellate cells. Zhonghua Yi Xue Za Zhi. 2004; 84: 1240-2.

31. Abreu JG, Ketpura NI, Reversade B, De Robertis EM. Connective-tissue growth factor (CTGF) modulates cell signalling by BMP and TGF-beta. Nat Cell Biol. 2002; 4: 599-604

32. Massague J. Identification of receptors for type-beta transforming growth factor. Methods Enzymol. 1987; 146: 174-95.

33. Nelson DR, Lauwers GY, Lau JY, Davis GL. Interleukin 10 treatment reduces fibrosis in patients with chronic hepatitis C: a pilot trial of interferon nonresponders. Gastroenterology. 2000; 118: 655-60.

34. Elsasser HP, Adler G, Kern HF. Time course and cellular source of pancreatic regeneration following acute pancreatitis in the rat. Pancreas. 1986; 1: 421-9.

35. Elsasser HP, Adler G, Kern HF. Fibroblast structure and function during regeneration from hormone-induced acute pancreatitis in the rat. Pancreas. 1989; 4: 169-78.

36. Friess H, Lu Z, Riesle E, Uhl W, Brundler AM, Horvath L, et al. Enhanced expression of TGF-betas and their receptors in human acute pancreatitis. Ann Surg. 1998; 227: 95-104.

37. Weidenbach H, Lerch MM, Turi S, Bachem M, Adler G. Failure of a prolyl 4-hydroxylase inhibitor to alter extracellular matrix deposition during experimental pancreatitis. Digestion. 1997; 58: 50-7.

38. Demols A, Van Laethem JL, Quertinmont E, Degraef C, Delhaye M, Geerts A, et al. Endogenous interleukin-10 modulates fibrosis and regeneration in experimental chronic pancreatitis. Am J Physiol Gastrointest Liver Physiol. 2002; 282: G1105-12.

39. Zhang LJ, Zheng WD, Shi MN, Wang XZ. Effects of interleukin-10 on activation and apoptosis of hepatic stellate cells in fibrotic rat liver. World J Gastroenterol. 2006; 12: 1918-23.

40. Shi MN, Huang YH, Zheng WD, Zhang LJ, Chen ZX, Wang XZ. Relationship between transforming growth factor beta1 and anti-fibrotic effect of interleukin-10. World J Gastroenterol. 2006; 12: 2357-62.

41. Luttenberger T, Schmid-Kotsas A, Menke A, Siech M, Beger H, Adler G, et al Platelet-derived growth factors stimulate proliferation and extracellular matrix synthesis of pancreatic stellate cells: implications in pathogenesis of pancreas fibrosis. Lab Invest. 2000; 80: 47-55.

42. Masamune A, Suzuki N, Kikuta K, Ariga H, Hayashi S, Takikawa T, et al. Connexins regulate cell functions in pancreatic stellate cells. Pancreas. 2013; 42: 308-16.
43. Fredriksson $\mathrm{L}, \mathrm{Li} \mathrm{H}$, Eriksson U. The PDGF family: four gene products form five dimeric isoforms. Cytokine Growth Factor Rev. 2004; 15: 197-204.

44. Yuzawa S, Kano MR, Einama T, Nishihara H. PDGFRbeta expression in tumor stroma of pancreatic adenocarcinoma as a reliable prognostic marker. Med Oncol. 2012; 29: 2824-30.

45. Apte MV, Haber PS, Darby SJ, Rodgers SC, McCaughan GW, Korsten MA, et al. Pancreatic stellate cells are activated by proinflammatory cytokines: implications for pancreatic fibrogenesis. Gut. 1999; 44: 534-41.

46. Masamune A, Kikuta K, Satoh M, Kume K, Shimosegawa T. Differential roles of signaling pathways for proliferation and migration of rat pancreatic stellate cells. Tohoku J Exp Med. 2003; 199: 69-84.

47. Lee BJ, Lee HS, Kim CD, Jung SW, Seo YS, Kim YS, et al. The Effects of Combined Treatment with an HMG-CoA Reductase Inhibitor and PPARgamma Agonist on the Activation of Rat Pancreatic Stellate Cells. Gut Liver. 2012; 6: 262-9.

48. Jaster R, Sparmann G, Emmrich J, Liebe S. Extracellular signal regulated kinases are key mediators of mitogenic signals in rat pancreatic stellate cells. Gut. 2002. 51: 579-84

49. Ide T, Kitajima Y, Miyoshi A, Ohtsuka T, Mitsuno M, Ohtaka K, et al. Tumor-stromal cell interaction under hypoxia increases the invasiveness of pancreatic cancer cells through the hepatocyte growth factor/c-Met pathway. Int J Cancer. 2006; 119: 2750-9.

50. Kitajima Y, Ide T, Ohtsuka T, Miyazaki K. Induction of hepatocyte growth factor activator gene expression under hypoxia activates the hepatocyte growth factor/c-Met system via hypoxia inducible factor-1 in pancreatic cancer. Cancer Sci. 2008; 99: 1341-7.

51. Chen YT, Chen FW, Chang TH, Wang TW, Hsu TP, Chi JY, et al. Hepatoma-derived growth factor supports the antiapoptosis and profibrosis of pancreatic stellate cells. Cancer Lett. 2019; 457: 180-90.

52. Masamune A, Nakano E, Hamada S, Takikawa T, Yoshida N, Shimosegawa T. Alteration of the microRNA expression profile during the activation of pancreatic stellate cells. Scand J Gastroenterol. 2014; 49: 323-31.

53. Masamune A, Yoshida N, Hamada S, Takikawa T, Nabeshima T, Shimosegawa T. Exosomes derived from pancreatic cancer cells induce activation and profibrogenic activities in pancreatic stellate cells. Biochem Biophys Res Commun. 2018; 495: 71-7.

54. Charrier A, Chen R, Chen L, Kemper S, Hattori T, Takigawa M, et al. Connective tissue growth factor (CCN2) and microRNA-21 are components of a positive feedback loop in pancreatic stellate cells (PSC) during chronic pancreatitis and are exported in PSC-derived exosomes. J Cell Commun Signal. 2014; 8: 147-56.

55. Yan B, Cheng L, Jiang Z, Chen K, Zhou C, Sun L, et al. Resveratrol Inhibits ROS-Promoted Activation and Glycolysis of Pancreatic Stellate Cells via Suppression of miR-21. Oxid Med Cell Longev. 2018; 2018: 1346958.

56. Schnittert $J$, Kuninty PR, Bystry $T F$, Brock $R$, Storm $G$, Prakash J. Anti-microRNA targeting using peptide-based nanocomplexes to inhibit differentiation of human pancreatic stellate cells. Nanomedicine (Lond). 2017; 12: $1369-84$

57. Kuninty PR, Bojmar L, Tjomsland V, Larsson M, Storm G, Ostman A, et al. MicroRNA-199a and -214 as potential therapeutic targets in pancreatic stellate cells in pancreatic tumor. Oncotarget. 2016; 7: 16396-408.

58. Suzuki R, Asama H, Waragai $Y$, Takagi $T$, Hikichi $T$, Sugimoto $M$, et al. Fibrosis-related miRNAs as serum biomarkers for pancreatic ductal adenocarcinoma. Oncotarget. 2018; 9: 4451-60.

59. Asama H, Suzuki R, Hikichi T, Takagi T, Masamune A, Ohira H. MicroRNA let-7d targets thrombospondin-1 and inhibits the activation of human pancreatic stellate cells. Pancreatology. 2019; 19: 196-203.

60. Wang $H$, Jiang $Y$, Lu $M$, Sun $B$, Oiao $X$, Xue $D$, et al. STX12 IncRNA/miR-148a/SMAD5 participate in the regulation of pancreatic stellate cell activation through a mechanism involving competing endogenous RNA. Pancreatology. 2017; 17: 237-46.

61. Liu $\mathrm{H}, \mathrm{Yu} \mathrm{K}$, Ma $\mathrm{P}$, Xiong $\mathrm{L}$, Wang $\mathrm{M}$, Wang $\mathrm{W}$. Long noncoding RNA myocardial infarction-associated transcript regulated the pancreatic stellate cell activation to promote the fibrosis process of chronic pancreatitis. J Cell Biochem. 2019; 120: 9547-55.

62. Xu M, Wang G, Zhou H, Cai J, Li P, Zhou M, et al. TGF-beta1-miR-200a-PTEN induces epithelial-mesenchymal transition and fibrosis of pancreatic stellate cells. Mol Cell Biochem. 2017; 431: 161-8.

63. Zeki S, Miura S, Suzuki H, Watanabe N, Adachi M, Yokoyama H, et al. Xanthine oxidase-derived oxygen radicals play significant roles in the development of chronic pancreatitis in WBN/Kob rats. J Gastroenterol Hepatol. 2002; 17: 606-16.

64. Yoo BM, Oh TY, Kim YB, Yeo M, Lee JS, Surh YJ, et al. Novel antioxidant ameliorates the fibrosis and inflammation of cerulein-induced chronic pancreatitis in a mouse model. Pancreatology. 2005; 5: 165-76.

65. Xue R, Wang J, Yang L, Liu X, Gao Y, Pang Y, et al. Coenzyme O10 Ameliorates Pancreatic Fibrosis via the ROS-Triggered mTOR Signaling Pathway. Oxid Med Cell Longev. 2019; 2019: 8039694.

66. Xue R, Yang J, Wu J, Meng Q, Hao J. Coenzyme Q10 inhibits the activation of pancreatic stellate cells through $\mathrm{PI} 3 \mathrm{~K} / \mathrm{AKT} / \mathrm{mTOR}$ signaling pathway. Oncotarget. 2017; 8: 92300-11.

67. Apte MV, Norton ID, Wilson IS. Ethanol induced acinar cell injury. Alcohol Alcohol Suppl. 1994; 2: 365-8.

68. Wilson JS, Apte MV. Role of alcohol metabolism in alcoholic pancreatitis. Pancreas. 2003; 27: 311-5. 
69. McCarroll JA, Phillips PA, Park S, Doherty E, Pirola RC, Wilson JS, et al. Pancreatic stellate cell activation by ethanol and acetaldehyde: is it mediated by the mitogen-activated protein kinase signaling pathway? Pancreas. 2003; 27: $150-60$.

70. Lee AT, Xu Z, Pothula SP, Patel MB, Pirola RC, Wilson JS, et al. Alcohol and cigarette smoke components activate human pancreatic stellate cells: implications for the progression of chronic pancreatitis. Alcohol Clin Exp Res. 2015; 39: 2123-33.

71. Apte MV, Phillips PA, Fahmy RG, Darby SJ, Rodgers SC, McCaughan GW, et al. Does alcohol directly stimulate pancreatic fibrogenesis? Studies with rat pancreatic stellate cells. Gastroenterology. 2000; 118: 780-94.

72. Xue J, Zhao Q, Sharma V, Nguyen LP, Lee YN, Pham KL, et al. Aryl Hydrocarbon Receptor Ligands in Cigarette Smoke Induce Production of Interleukin-22 to Promote Pancreatic Fibrosis in Models of Chronic Pancreatitis. Gastroenterology. 2016; 151: 1206-17.

73. Asaumi H, Watanabe S, Taguchi M, Tashiro M, Otsuki M. Externally applied pressure activates pancreatic stellate cells through the generation of intracellular reactive oxygen species. Am J Physiol Gastrointest Liver Physiol. 2007; 293: G972-8

74. Watanabe S, Nagashio Y, Asaumi H, Nomiyama Y, Taguchi M, Tashiro M, et al. Pressure activates rat pancreatic stellate cells. Am J Physiol Gastrointest Liver Physiol. 2004; 287: G1175-81.

75. Hong OK, Lee SH, Rhee M, Ko SH, Cho JH, Choi YH, et al. Hyperglycemia and hyperinsulinemia have additive effects on activation and proliferation of pancreatic stellate cells: possible explanation of islet-specific fibrosis in type 2 diabetes mellitus. J Cell Biochem. 2007; 101: 665-75

76. Ko SH, Hong OK, Kim JW, Ahn YB, Song KH, Cha BY, et al. High glucose increases extracellular matrix production in pancreatic stellate cells by activating the renin-angiotensin system. J Cell Biochem. 2006; 98: 343-55.

77. Nomiyama Y, Tashiro M, Yamaguchi T, Watanabe S, Taguchi M, Asaumi H, et al. High glucose activates rat pancreatic stellate cells through protein kinase $\mathrm{C}$ and p38 mitogen-activated protein kinase pathway. Pancreas. 2007; 34: 364-72.

78. Kiss K, Baghy K, Spisak S, Szanyi S, Tulassay Z, Zalatnai A, et al. Chronic hyperglycemia induces trans-differentiation of human pancreatic stellate cells and enhances the malignant molecular communication with human pancreatic cancer cells. PLoS One. 2015; 10: e0128059.

79. Nielsen N, Kondratska K, Ruck T, Hild B, Kovalenko I, Schimmelpfennig S, et al. TRPC6 channels modulate the response of pancreatic stellate cells to hypoxia. Pflugers Arch. 2017; 469: 1567-77.

80. Storck H, Hild B, Schimmelpfennig S, Sargin S, Nielsen N, Zaccagnino A, et al. Ion channels in control of pancreatic stellate cell migration. Oncotarget. 2017; 8: 769-84.

81. Fels B, Nielsen N, Schwab A. Role of TRPC1 channels in pressure-mediated activation of murine pancreatic stellate cells. Eur Biophys J. 2016; 45: 657-70.

82. Gerasimenko JV, Peng S, Tsugorka T, Gerasimenko OV. $\mathrm{Ca}(2+)$ signalling underlying pancreatitis. Cell Calcium. 2018; 70: 95-101.

83. Gryshchenko O, Gerasimenko JV, Gerasimenko OV, Petersen $\mathrm{OH}$. $\mathrm{Ca}(2+)$ signals mediated by bradykinin type 2 receptors in normal pancreatic stellate cells can be inhibited by specific $\mathrm{Ca}(2+)$ channel blockade. J Physiol. 2016; 594: 281-93.

84. Won JH, Zhang Y, Ji B, Logsdon CD, Yule DI. Phenotypic changes in mouse pancreatic stellate cell $\mathrm{Ca} 2+$ signaling events following activation in culture and in a disease model of pancreatitis. Mol Biol Cell. 2011; 22: 421-36.

85. Ferdek PE, Jakubowska MA, Gerasimenko JV, Gerasimenko OV, Petersen OH. Bile acids induce necrosis in pancreatic stellate cells dependent on calcium entry and sodium-driven bile uptake. J Physiol. 2016; 594: 6147-64.

86. Jakubowska MA, Ferdek PE, Gerasimenko OV, Gerasimenko JV, Petersen OH. Nitric oxide signals are interlinked with calcium signals in normal pancreatic stellate cells upon oxidative stress and inflammation. Open Biol. 2016; 6 .

87. Samuel I, Zaheer A, Fisher RA. In vitro evidence for role of ERK, p38, and JNK in exocrine pancreatic cytokine production. J Gastrointest Surg. 2006; 10: 1376-83.

88. Chang L, Karin M. Mammalian MAP kinase signalling cascades. Nature. 2001; 410: $37-40$.

89. Pearson G, Robinson F, Beers Gibson T, Xu BE, Karandikar M, Berman K, et al. Mitogen-activated protein (MAP) kinase pathways: regulation and physiological functions. Endocr Rev. 2001; 22: 153-83.

90. Fang L, Zhan S, Huang C, Cheng X, Lv X, Si H, et al. TRPM7 channel regulates PDGF-BB-induced proliferation of hepatic stellate cells via PI3K and ERK pathways. Toxicol Appl Pharmacol. 2013; 272: 713-25.

91. Ameyar M, Wisniewska M, Weitzman JB. A role for AP-1 in apoptosis: the case for and against. Biochimie. 2003; 85: 747-52.

92. Hess J, Angel P, Schorpp-Kistner M. AP-1 subunits: quarrel and harmony among siblings. J Cell Sci. 2004; 117: 5965-73.

93. Masamune A, Kikuta K, Satoh M, Satoh A, Shimosegawa T. Alcohol activates activator protein-1 and mitogen-activated protein kinases in rat pancreatic stellate cells. J Pharmacol Exp Ther. 2002; 302: 36-42.

94. Schwer CI, Guerrero AM, Humar M, Roesslein M, Goebel U, Stoll P, et al. Heme oxygenase- 1 inhibits the proliferation of pancreatic stellate cells by repression of the extracellular signal-regulated kinase1/2 pathway. J Pharmacol Exp Ther. 2008; 327: 863-71.

95. Uchida $\mathrm{M}$, Ito $\mathrm{T}$, Nakamura $\mathrm{T}$, Igarashi $\mathrm{H}$, Oono $\mathrm{T}$, Fujimori $\mathrm{N}$, et al. ERK pathway and sheddases play an essential role in ethanol-induced CX3CL1 release in pancreatic stellate cells. Lab Invest. 2013; 93: 41-53.
96. Schwer CI, Stoll P, Goebel U, Buerkle H, Hoetzel A, Schmidt R. Effects of hydrogen sulfide on rat pancreatic stellate cells. Pancreas. 2012; 41: 74-83.

97. Kyriakis JM, Avruch J. Mammalian MAPK signal transduction pathways activated by stress and inflammation: a 10-year update. Physiol Rev. 2012; 92: 689-737.

98. Fitzner B, Sparmann G, Emmrich J, Liebe S, Jaster R. Involvement of AP-1 proteins in pancreatic stellate cell activation in vitro. Int J Colorectal Dis. 2004; 19: 414-20.

99. Masamune A, Kikuta K, Suzuki N, Satoh M, Satoh K, Shimosegawa T. A c-Jun NH2-terminal kinase inhibitor SP600125 (anthra[1,9-cd]pyrazole-6 (2H)-one) blocks activation of pancreatic stellate cells. J Pharmacol Exp Ther. 2004; 310: $520-7$

100. Kamata H, Honda S, Maeda S, Chang L, Hirata H, Karin M. Reactive oxygen species promote TNFalpha-induced death and sustained JNK activation by inhibiting MAP kinase phosphatases. Cell. 2005; 120: 649-61.

101. Sugden PH, Clerk A. "Stress-responsive" mitogen-activated protein kinases (c-Jun N-terminal kinases and p38 mitogen-activated protein kinases) in the myocardium. Circ Res. 1998; 83: 345-52.

102. Masamune A, Satoh M, Kikuta K, Sakai Y, Satoh A, Shimosegawa T. Inhibition of p38 mitogen-activated protein kinase blocks activation of rat pancreatic stellate cells. J Pharmacol Exp Ther. 2003; 304: 8-14.

103. Apte M, McCarroll J, Pirola R, Wilson J. Pancreatic MAP kinase pathways and acetaldehyde. Novartis Found Symp. 2007; 285: 200-11; discussion 11-6.

104. Takai Y, Sasaki T, Tanaka K, Nakanishi H. Rho as a regulator of the cytoskeleton. Trends Biochem Sci. 1995; 20: 227-31.

105. Masamune A, Kikuta K, Satoh M, Satoh K, Shimosegawa T. Rho kinase inhibitors block activation of pancreatic stellate cells. Br J Pharmacol. 2003; 140: 1292-302.

106. Hayden MS, West AP, Ghosh S. NF-kappaB and the immune response. Oncogene. 2006; 25: 6758-80.

107. Kikuta K, Masamune A, Satoh M, Suzuki N, Satoh $\mathrm{K}$, Shimosegawa $T$. Hydrogen peroxide activates activator protein-1 and mitogen-activated protein kinases in pancreatic stellate cells. Mol Cell Biochem. 2006; 291: 11-20.

108. Masamune A, Sakai Y, Kikuta K, Satoh M, Satoh A, Shimosegawa T. Activated rat pancreatic stellate cells express intercellular adhesion molecule-1 (ICAM-1) in vitro. Pancreas. 2002; 25: 78-85.

109. Masamune A, Kikuta K, Watanabe T, Satoh K, Satoh A, Shimosegawa T. Pancreatic stellate cells express Toll-like receptors. J Gastroenterol. 2008; 43: 352-62.

110. Zhao W, Ajani JA, Sushovan G, Ochi N, Hwang R, Hafley M, et al. Galectin-3 Mediates Tumor Cell-Stroma Interactions by Activating Pancreatic Stellate Cells to Produce Cytokines via Integrin Signaling. Gastroenterology. 2018; 154: 1524-37 e6.

111. Tontonoz P, Spiegelman BM. Fat and beyond: the diverse biology of PPARgamma. Annu Rev Biochem. 2008; 77: 289-312.

112. Masamune A, Kikuta K, Satoh M, Sakai Y, Satoh A, Shimosegawa T. Ligands of peroxisome proliferator-activated receptor-gamma block activation of pancreatic stellate cells. J Biol Chem. 2002; 277: 141-7.

113. Shimizu K, Shiratori K, Kobayashi M, Kawamata H. Troglitazone inhibits the progression of chronic pancreatitis and the profibrogenic activity of pancreatic stellate cells via a PPARgamma-independent mechanism. Pancreas. 2004; 29: 67-74

114. Jaster R, Lichte P, Fitzner B, Brock P, Glass A, Karopka T, et al. Peroxisome proliferator-activated receptor gamma overexpression inhibits pro-fibrogenic activities of immortalised rat pancreatic stellate cells. J Cell Mol Med. 2005; 9: 670-82.

115. Shimizu K, Shiratori K, Hayashi N, Kobayashi M, Fujiwara T, Horikoshi H. Thiazolidinedione derivatives as novel therapeutic agents to prevent the development of chronic pancreatitis. Pancreas. 2002; 24: 184-90.

116. van Westerloo DJ, Florquin S, de Boer AM, Daalhuisen J, de Vos AF, Bruno MJ, et al. Therapeutic effects of troglitazone in experimental chronic pancreatitis in mice. Am J Pathol. 2005; 166: 721-8.

117. Hisada S, Shimizu K, Shiratori K, Kobayashi M. Peroxisome proliferator-activated receptor gamma ligand prevents the development of chronic pancreatitis through modulating NF-kappaB-dependent proinflammatory cytokine production and pancreatic stellate cell activation. Rocz Akad Med Bialymst. 2005; 50: 142-7.

118. Johnson CL, Weston JY, Chadi SA, Fazio EN, Huff MW, Kharitonenkov A, et al. Fibroblast growth factor 21 reduces the severity of cerulein-induced pancreatitis in mice. Gastroenterology. 2009; 137: 1795-804.

119. Roy SK, Srivastava RK, Shankar S. Inhibition of PI3K/AKT and MAPK/ERK pathways causes activation of FOXO transcription factor, leading to cell cycle arrest and apoptosis in pancreatic cancer. J Mol Signal. 2010; 5: 10

120. Coelho RP, Yuelling LM, Fuss B, Sato-Bigbee C. Neurotrophin-3 targets the translational initiation machinery in oligodendrocytes. Glia. 2009; 57: 1754-64.

121. Nishida A, Andoh A, Shioya M, Kim-Mitsuyama S, Takayanagi A, Fujiyama Y. Phosphatidylinositol 3-kinase/Akt signaling mediates interleukin-32alpha induction in human pancreatic periacinar myofibroblasts. Am J Physiol Gastrointest Liver Physiol. 2008; 294: G831-8.

122. Schwer CI, Mutschler M, Stoll P, Goebel U, Humar M, Hoetzel A, et al. Carbon monoxide releasing molecule- 2 inhibits pancreatic stellate cell proliferation by activating p38 mitogen-activated protein kinase/heme oxygenase-1 signaling. Mol Pharmacol. 2010; 77: 660-9.

123. Schwer CI, Stoll P, Rospert S, Fitzke E, Schallner N, Burkle H, et al. Carbon monoxide releasing molecule-2 CORM-2 represses global protein synthesis by 
inhibition of eukaryotic elongation factor eEF2. Int J Biochem Cell Biol. 2013; 45: 201-12.

124. Zhang X, Jin T, Huang X, Liu X, Liu Z, Jia Y, et al. Effects of the tumor suppressor PTEN on biological behaviors of activated pancreatic stellate cells in pancreatic fibrosis. Exp Cell Res. 2018; 373: 132-44.

125. Cui LH, Li CX, Zhuo YZ, Yang L, Cui NQ, Zhang SK. Saikosaponin d ameliorates pancreatic fibrosis by inhibiting autophagy of pancreatic stellate cells via PI3K/Akt/mTOR pathway. Chem Biol Interact. 2019; 300: 18-26.

126. Endo S, Nakata K, Ohuchida K, Takesue S, Nakayama H, Abe T, et al. Autophagy Is Required for Activation of Pancreatic Stellate Cells, Associated With Pancreatic Cancer Progression and Promotes Growth of Pancreatic Tumors in Mice. Gastroenterology. 2017; 152: 1492-506 e24.

127. Li CX, Cui LH, Zhuo YZ, Hu JG, Cui NQ, Zhang SK. Inhibiting autophagy promotes collagen degradation by regulating matrix metalloproteinases in pancreatic stellate cells. Life Sci. 2018; 208: 276-83.

128. Shen M, Chen K, Lu J, Cheng P, Xu L, Dai W, et al. Protective effect of astaxanthin on liver fibrosis through modulation of TGF-beta1 expression and autophagy. Mediators Inflamm. 2014; 2014: 954502.

129. Wu L, Zhang Q, Mo W, Feng J, Li S, Li J, et al. Quercetin prevents hepatic fibrosis by inhibiting hepatic stellate cell activation and reducing autophagy via the TGF-beta1/Smads and PI3K/Akt pathways. Sci Rep. 2017; 7: 9289.

130. Yu DK, Zhang CX, Zhao SS, Zhang SH, Zhang H, Cai SY, et al. The anti-fibrotic effects of epigallocatechin-3-gallate in bile duct-ligated cholestatic rats and human hepatic stellate LX-2 cells are mediated by the PI3K/Akt/Smad pathway. Acta Pharmacol Sin. 2015; 36: 473-82.

131. Silva CM. Role of STATs as downstream signal transducers in Src family kinase-mediated tumorigenesis. Oncogene. 2004; 23: 8017-23.

132. Masamune A, Satoh M, Kikuta K, Suzuki N, Shimosegawa T. Activation of JAK-STAT pathway is required for platelet-derived growth factor-induced proliferation of pancreatic stellate cells. World J Gastroenterol. 2005; 11: 3385-91.

133. Kim H. Cerulein pancreatitis: oxidative stress, inflammation, and apoptosis. Gut Liver. 2008; 2: 74-80.

134. Wu JW, Hu M, Chai J, Seoane J, Huse M, Li C, et al. Crystal structure of a phosphorylated Smad2. Recognition of phosphoserine by the MH2 domain and insights on Smad function in TGF-beta signaling. Mol Cell. 2001; 8: 1277-89.

135. Shi Y, Hata A, Lo RS, Massague J, Pavletich NP. A structural basis for mutational inactivation of the tumour suppressor Smad4. Nature. 1997; 388: 87-93.

136. Itoh $\mathrm{F}$, Asao $\mathrm{H}$, Sugamura $\mathrm{K}$, Heldin $\mathrm{CH}$, ten Dijke $\mathrm{P}$, Itoh $\mathrm{S}$. Promoting bone morphogenetic protein signaling through negative regulation of inhibitory Smads. EMBO J. 2001; 20: 4132-42.

137. Ohnishi H, Miyata T, Yasuda H, Satoh Y, Hanatsuka K, Kita H, et al. Distinct roles of Smad2-, Smad3-, and ERK-dependent pathways in transforming growth factor-beta1 regulation of pancreatic stellate cellular functions. J Biol Chem. 2004; 279: 8873-8.

138. Hama $\mathrm{K}$, Ohnishi $\mathrm{H}$, Aoki $\mathrm{H}$, Kita $\mathrm{H}$, Yamamoto $\mathrm{H}$, Osawa $\mathrm{H}$, et al. Angiotensin II promotes the proliferation of activated pancreatic stellate cells by Smad7 induction through a protein kinase $C$ pathway. Biochem Biophys Res Commun. 2006; 340: 742-50.

139. Li L, Bachem MG, Zhou S, Sun Z, Chen J, Siech M, et al. Pancreatitis-associated protein inhibits human pancreatic stellate cell MMP-1 and -2, TIMP-1 and -2 secretion and RECK expression. Pancreatology. 2009; 9: 99-110.

140. Lee H, Lim C, Lee J, Kim N, Bang S, Lee H, et al. TGF-beta signaling preserves RECK expression in activated pancreatic stellate cells. J Cell Biochem. 2008; 104: 1065-74.

141. Gao X, Cao Y, Staloch DA, Gonzales MA, Aronson JF, Chao C, et al. Bone morphogenetic protein signaling protects against cerulein-induced pancreatic fibrosis. PLoS One. 2014; 9: e89114.

142. Shinozaki S, Ohnishi H, Hama K, Kita H, Yamamoto H, Osawa H, et al. Indian hedgehog promotes the migration of rat activated pancreatic stellate cells by increasing membrane type- 1 matrix metalloproteinase on the plasma membrane. J Cell Physiol. 2008; 216: 38-46.

143. Bailey JM, Swanson BJ, Hamada T, Eggers JP, Singh PK, Caffery T, et al. Sonic hedgehog promotes desmoplasia in pancreatic cancer. Clin Cancer Res. 2008; 14: 5995-6004.

144. Li X, Wang Z, Ma Q, Xu Q, Liu H, Duan W, et al. Sonic hedgehog paracrine signaling activates stromal cells to promote perineural invasion in pancreatic cancer. Clin Cancer Res. 2014; 20: 4326-38.

145. Han L, Ma J, Duan W, Zhang L, Yu S, Xu Q, et al. Pancreatic stellate cells contribute pancreatic cancer pain via activation of $\mathrm{sHH}$ signaling pathway. Oncotarget. 2016; 7: 18146-58

146. Tsang SW, Zhang H, Lin C, Xiao H, Wong M, Shang H, et al. Rhein, a natural anthraquinone derivative, attenuates the activation of pancreatic stellate cells and ameliorates pancreatic fibrosis in mice with experimental chronic pancreatitis. PLoS One. 2013; 8: e82201.

147. Means AL. Pancreatic stellate cells: small cells with a big role in tissue homeostasis. Lab Invest. 2013; 93: 4-7.

148. Lee JJ, Perera RM, Wang H, Wu DC, Liu XS, Han S, et al. Stromal response to Hedgehog signaling restrains pancreatic cancer progression. Proc Natl Acad Sci US A. 2014; 111: E3091-100.

149. Rhim AD, Oberstein PE, Thomas DH, Mirek ET, Palermo CF, Sastra SA, et al. Stromal elements act to restrain, rather than support, pancreatic ductal adenocarcinoma. Cancer Cell. 2014; 25: 735-47. 